\title{
Calculation and Analysis on Characteristic of hydraulic sheave buffer by AMESim
}

\author{
K. Bi, X. Li, Y.M. Wei, Z.Y. Tang \& G. Wu \\ Naval University of Engineering, Wuhan, China
}

\begin{abstract}
In order to enhance the sheave buffer damping efficiency of the carrier-based aircraft arresting system, and improve the damping characteristics of the buffer and the suitability of the load, the multi-hole hydraulic buffer is brought to substitute the conventional hydraulic buffer, the two type hydraulic buffer model are built and simulated based on the AMEsim. This study shows that the damping efficiency of the multihole hydraulic buffer is $10.56 \%$ higher than the conventional hydraulic buffer.
\end{abstract}

KEYWORD: Sheave buffer; Multi-hole hydraulic buffer; AMEsim; Buffer efficiency

\section{INTRODUCTION}

Sheave buffer is enclosed between the tail hook and the main arresting device, the main functions of which are tensioning arresting cable, reducing stress wave, diminishing impulse of landing. With the increasing mass and velocity of modern aircraft, the impulse of landing augments. Sheave buffer has been added into the aircraft carrier arresting gear, since MK7-3 (X. Ou, 2005) (C.B Zhu, 2009), preventing arresting cable from parting caused by instantaneous excessive tension.

MK7-3 type sheave buffer is now equipped on aircraft carrier, adopting the conventional piston and the hydraulic cylinder as the main body of the buffer, the characteristics of which are simple structure and fast response, but relatively low efficiency and the damping characteristic no changing with the load and the piston stroke. In comparison, multi-hole hydraulic buffer, which has the advantages of compact structure, large energy absorption, no rebound and high efficiency, prolonging the impact load, is commonly used in large impact load, speed of which is higher than that of $2 \mathrm{~m} / \mathrm{s}$, on the mechanical. In this paper, sheave buffer is taken as the main research object, multi-hole hydraulic buffer is used to replace the conventional hydraulic cylinder (D.L. Rong et al, 2012), at the mean time Studies on performance optimization is made.

\section{SHEAVE BUFFER MATHEMATICAL MODEL}

\subsection{Mathematical model of MK7-3 type sheave buffer}

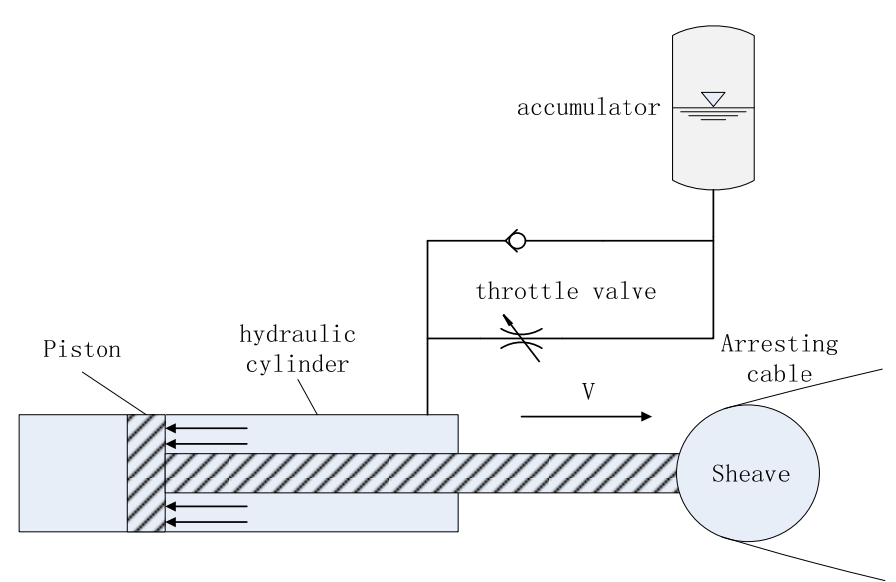

Fig 1. Structure sketch of MK7-3 sheave buffer

Shown in Fig.1 is the structure sketch of MK7-3 sheave buffer. After the aircraft landed, its tail hook pull the piston rod out by the arresting cable, then, part of the hydraulic oil in the rod cavity of Hydraulic cylinder goes into the accumulator through the throttle valve. During the piston motion, the damping force, caused by the difference of the force between the two ends of the piston, buffers the carrier aircraft. 


$$
F_{\mathrm{z}} \Delta t=M_{\text {load }} \Delta v
$$

where $M_{\text {load }}=$ mass of impact load and piston; $\Delta v=$ velocity variables; $F z=$ buffer damping force; $\Delta t=$ buffer action time.

$$
F_{\mathrm{z}}=A_{\mathrm{e}} P_{t}
$$

where $A_{\mathrm{e}}=\pi\left(D_{p}^{2}-d_{p}^{2}\right) / 4 ; A_{e}=$ piston effective stress area; $D_{p}=$ hydraulic cylinder diameter; $d_{p}=$ piston rod diameter; $P_{t}=$ rod port pressure.

\subsection{Mathematical model of Multi-hole hydraulic buffer}

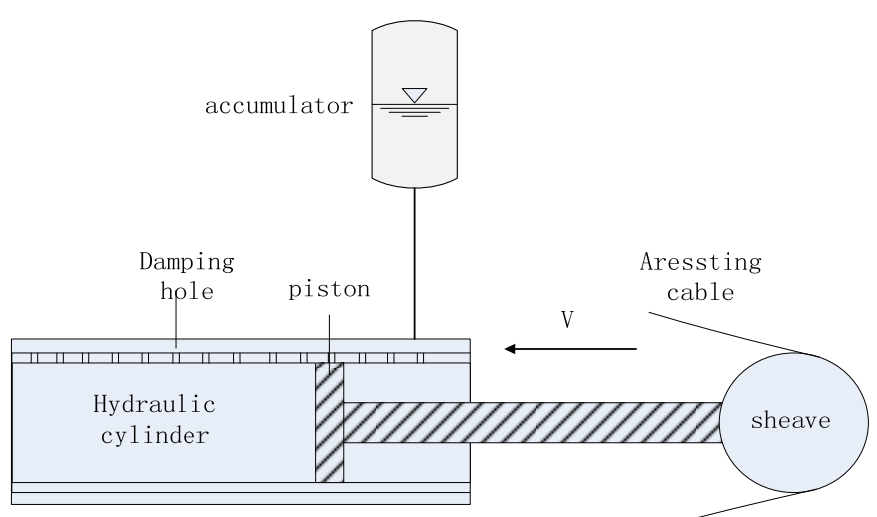

Fig 2. Structure sketch of multi-hole hydraulic buffer

Shown in Fig. 2 is the sheave buffer, which is constructed by the porous Multi-hole hydraulic buffer instead of the conventional hydraulic cylinder. During the buffer working, the tail hook presses the piston rod by arresting cable and sheaves. Hydraulic oil in the no rod cavity of hydraulic cylinder enters the rod cavity through the damping hole, because the piston rod has the volume, so part of the hydraulic oil enters the accumulator, and the piston gets reset by the energy of the accumulator.

Compared to the MK7-3 type sheave buffer, multi-hole hydraulic buffer, using the throttle orifice, adjust the hydraulic oil flow from the buffer into the storage. Due to the orifice area $A_{d}$ is changing with the piston stroke, so the damping force of the damping device could be adjusted by orifice position, thereby ensuring higher damping efficiency.

$$
q=C_{\mathrm{d}} A \sqrt{\frac{2 \Delta P}{\rho}}
$$

where $q=$ flux of orifice; $C_{d}=$ discharge coefficient; $A_{h}=$ orifice area; $\rho=$ hydraulic oil density.

Due to the working process of the accumulator is shorter, the working process of the accumulator can approximate to energy dissipation, and the buffer working process is an isentropic process.
$P_{\mathrm{ct}} V_{c t}^{1.4}=P_{\mathrm{c} 0} V_{c 0}^{1.4}=C$

where $P_{c 0}=$ accumulator initial pressure; $V_{c 0}=$ accumulator initial volume.

Displacement of the piston rod is $L t$, sheave buffer hydraulic oil continuity equation is:

$A_{\mathrm{e} t} L_{t}=C_{\mathrm{d}} A \sqrt{\frac{2 \Delta P}{\rho}} \Delta t+\frac{V_{0} \Delta P}{K}$

where $K=$ hydraulic oil elastic modulus.

Equation (5) left is the hydraulic oil decrement in hydraulic cylinder, Equation (5) right is the volume of hydraulic oil through the orifice and the volume of hydraulic oil compressed.

$$
A_{\mathrm{d}}=N A_{S} \lambda(L)
$$

where $A_{s}=$ single damping hole area; $N=$ number of damping holes; $\lambda(L)=$ coefficient with the piston displacement of orifice.

$$
F_{\mathrm{z}}=A_{\mathrm{p}} P_{t}
$$

\subsection{Modeling based on AMESim}

First enter the AMESim environment of the sketch mode (Wang Yunfeng et al, 2008) (H.Y.Li et al, 2011) (Liu Yuxin et al, 2014). Then, according to hydraulic system diagrams 1 and 2, System model of sheave buffer is established. Using the hydraulic components, related to AMESim software database.

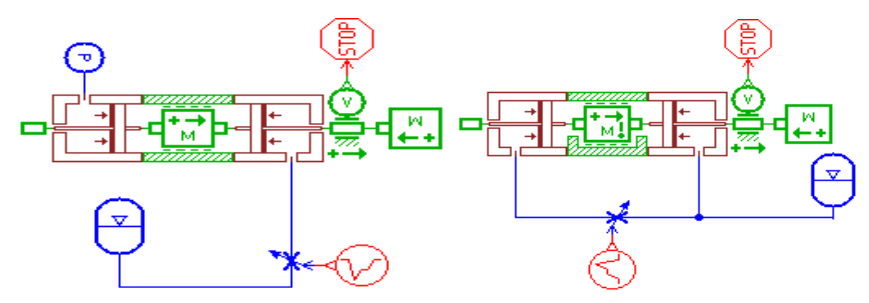

Fig 3. Sheave buffer model on AMEsim

Under the ASMEsim environment, the MK7-3 type sheave buffer and the multi-hole hydraulic buffer are modeled. It turns out that Figure 3 (a) is the AMESim model of the MK7-3 type sheave buffer, and figure 3 (b) is the AMESim model of multihole hydraulic buffer. The damping piston is simplified to be a mass and a spring damping mechanism, the damping hole parameters of a fixed damping hole and a multi-hole damper are respectively set.

\section{SIMULATION AND DATA ANALYSIS}

Selecting Mathematical model in hydraulic system components shown in figure 3, setting the parame- 
ters. Two kinds of buffer device simulation using the same impact load and velocity, and set the same stop terminal velocity, initial pressure accumulator is the same, and two buffers impact loads are the same impact energy.

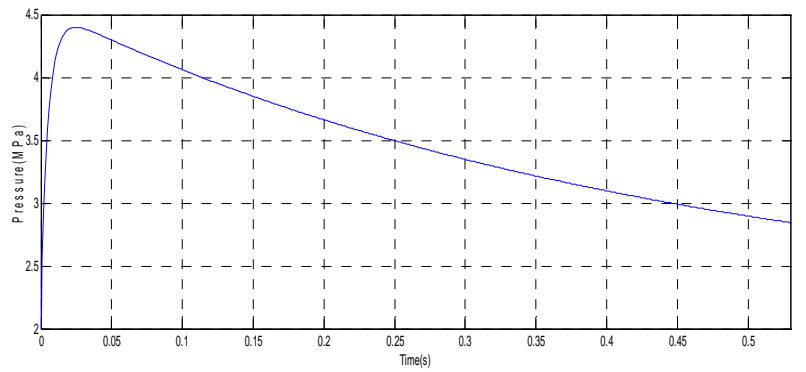

Fig 4. Simulation curve of MK7-3 sheave buffer rod port pressure

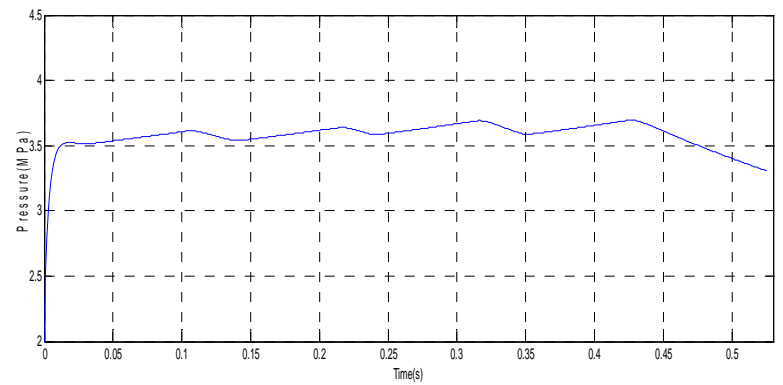

Fig 5. Simulation curve of multi-hole hydraulic buffer head port pressure

Using AMESim and Matlab for calculation and analysis of simulation data, as shown in Figure 4 and 5 is the hydraulic cylinder pressure $\mathrm{P}_{\mathrm{p}}$ of MK7-3 type sheave buffer and multi-hole hydraulic buffer. MK7-3 type sheave buffer will achieve maximum pressure in the initial shock, making it easy to reach cable tension limit in a very short time. But multihole hydraulic buffer maintain its' peak pressure relatively low in the initial shock, due to the large throttle area. Moreover, with the increase of the piston stroke, the pressure difference reducing, the throttle area decreasing, the average pressure is kept comparatively high, making arresting cable being kept in tensioned state. In conclusion, when it comes to the working pressure peak of two kinds of buffer hydraulic cylinder, multi-hole hydraulic buffer is $15.94 \%$ lower than the fixed throttle area hydraulic buffer, but $5.7 \%$ higher on the average working pressure.

Shock-isolation efficiency is usually used to measure the performance of a buffer, which means the area ratio of the rectangle, surrounded by the buffer force - the actual travel area and the maximum buffer capacity and a buffer stroke. Under the same impact energy, the result of simulation calculation is that shock-isolation efficiency of fixed orifice is 0.7959 , while that of multi-hole hydraulic buffer is 0.9015.which means the multi-hole hydraulic buffer, Compared with the MK7-3 type buffer ,is more efficient, and the damping force function is more stable.

\section{CONCLUSION}

Shock-isolation efficiency of multi-hole hydraulic buffer, in contrast with the fixed throttle area buffer, is $10.56 \%$ higher. From the simulation analysis, consequence could be made that the damping force of the multi-hole hydraulic buffer is higher than that of the MK7-3 type buffer with the fixed damping area, making the tension of the block more stable, arresting cable kept in tensioned state, the success rate of arresting improve and the life span of the arresting cable prolonged.

\section{REFERENCES}

C.B Zhu. Modern carrier arresting gear. Shipboard Weapons. 2009, (10):75-79.

D.L.Rong\& G.Wu\& J.Y.Lu et al. Research on the application of multi-hole hydraulic buffer in the arresting system .Ship and Ocean Engineering. 2012, 41(5):156-158.

H.Y.Li\& X.Y.Cheng. Simulation and optimization of dynamic characteristics of hydraulic cylinder system based on AMESim .Journal of Wuhan University of Science and Technology. 2011, 34(3):215-217.

Liu Yuxin Huang Jinghan Guo Leilei Lu Zhengyue Zhang Pingge. Study on pressure fluctuation of accumulator with AMESim,Coal mine electromechanical .2014,(6):26-27.

S.Sun. Simulation and optimization of multi-hole hydraulic buffer design[D]. DaLian: Dalian University of Technology.

Wang Yunfeng Chen Yongqing Zhao Xinze Tan Zongqi. Simulation analysis of main structure parameters of hydraulic buffer on AMESsim. Hoisting and Conveying Machinery. 2008, (5):79-82.

X.Ou. Carrier arresting gear. The Modern Ship.2005, (9): 4547.

Yang Bing heng $\mathrm{Bi}$ Yuquan Huang Kui Wang Haidong .Dynamic analysis of MK7-3 type arresting device buffer system. Ship science and technology.2011, 33 (3):141-143. 